\title{
A STUDY OF DESIGN FLEXIBLE FORCE OUTPUT OF COMPLIANT BISTABLE MECHANISM WITH LIMITED SPACE
}

\author{
TRAN NGOC DANG KHOA \\ Falcuty of mechanical engineering, Industrial University of Ho Chi Minh City; \\ tranngocdangkhoa@iuh.edu.vn
}

\begin{abstract}
This paper reports a new compliant bistable micromechanism (BM) with the flexibility of force output under a space constraint. The mechanism has four Bézier curved beams and a shuttle mass at its center. Bézier curves offer high flexibility for design of beam shapes of BMs. Compared to the conventional BMs with cosine curved beams and slanted straight beams, the BM with Bézier curved beam can be designed to have smaller switching forces under the same device area and thickness.
\end{abstract}

Keywords. Bézier curve, bistable, micromechanism.

\section{INTRODUCTION}

BMs are commonly used as switches, accelerometers, valves, in a wide range of sizes from macro to micro scales. Various profiles of beams of BMs have been utilized. Qiu et al. [1] employed a cosine curved beam structure in their BM. In order to adjust force-deflection (f-d) curve of the BM under an area footprint constraint, the thickness and the width of beams should be modulated. Wu et al. [2] presented a BM with slanted straight beam structure. Once a space constraint of the device is imposed, the length, the width, the thickness and the inclination angle of the slanted straight beam can be varied to meet the force output requirement besides material properties of the beam structure. A compliant bistable mechanism with many straight lines for nearly equal switching forces in the forward and backward directions is developed [3, 4]. The mechanism flexibility is taken advantage of the design of a bistable mechanism with nearly equal switching forces in the forward and backward directions. Pham and Wang [5] demonstrated a constant-force bistable mechanism, combine two cosin curve. The bistability of the mechanism originates from combined compression and bending of the beam structures. A stepped beam BM was investigated by Brake et al. [6]. The f-d curve of their BM was varied by changing beam thickness and width. Hwang et al. [7] investigated a compliant chevron-type BM. The structure of the mechanism is composed of hinge springs and stepped beam. The hinge spring provides an alternative to adjust the f-d curve of their BM. Wilcox et al. [8] introduced folded beam structures into their BMs. Their design is aimed to adjust force output of their BMs.

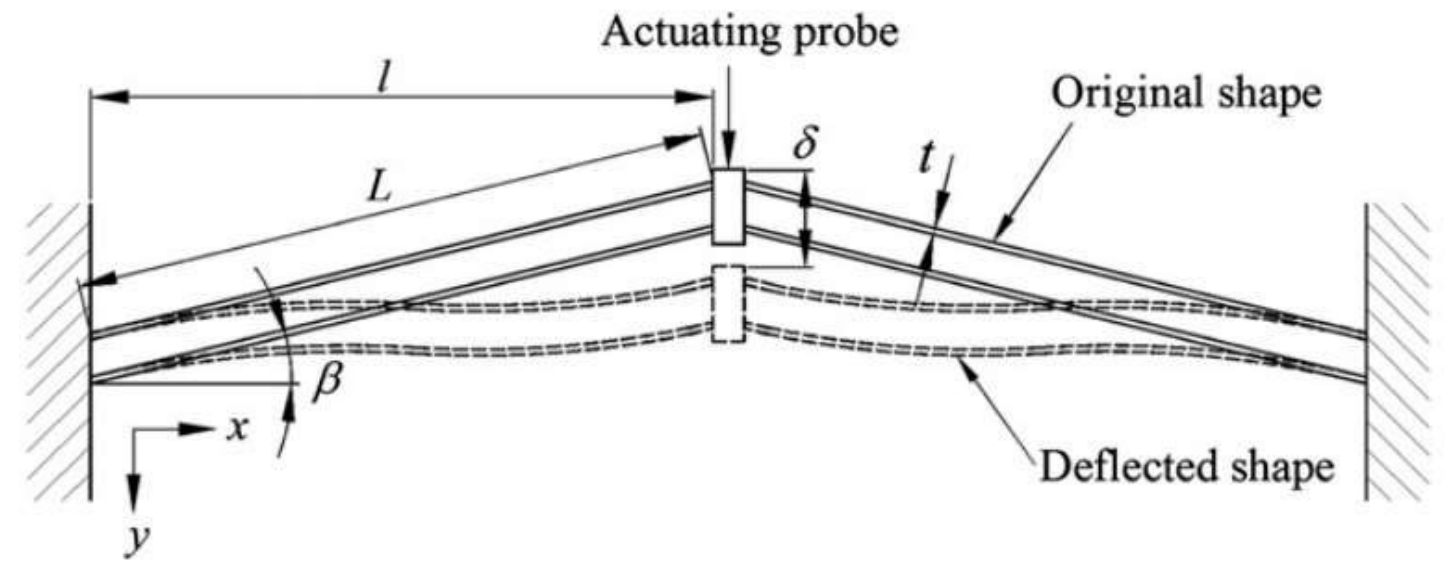

Fig. 1. A BM with staight beam [2]. 


\section{A STUDY OF DESIGN FLEXIBLE FORCE OUTPUT OF COMPLIANT BISTABLE MECHANISM WITH LIMITED SPACE}

Without adding to the device complexity, width and thickness of the beam structure of the conventional BMs with cosine curved beams and straight beams can be varied. In order to increase design flexibility of the BMs, parametric curves can be adopted for the profiles and the beam structure of BMs. Bézier curve is a parametric curve frequently used in computer graphics. It is also utilized to design in many applications. Wang and Nguyen [9] developed ultrasonic cutting horn based on Bézier profile. This hold is exploited for high displacement amplification in order to reduce the penetration force required to enter and cut materials. In this paper, a new BM with Bézier curved beams is investigated. Design of the BM is described. F-d curves and maximum stress of the BM under static loadings are analyzed by finite element analyses. The results of the presented device are compared with those of BMs with cosine beams and straight beams.

\section{CONCEPT OF BISTABLE MECHANISM}

Operation of bistable mechanism can be explain by "Ball-on-the-hill" anology [10]. Fig 2. Illustrates the stability of this mechanism. The balls in positions $\mathrm{A}$ and $\mathrm{C}$ are stablesince they would return to the same positions if a small disturbance was introduced. Theball in position B is unstable since any disturbance would cause the ball to roll from thehilltop. A mechanism is considered to be bistable if two points along its path of motion meet thedefinition of stability. These two points of stability are usually at the two extremes of therange of motion. Between the two stable positions, mechanisms are unstable. Thisinstability often results in the mechanism returning to a stable position even if it is leftbetween the two stable positions. This is especially beneficial for on/off switches or locking mechanisms which should not be able to remain in an in-between position.

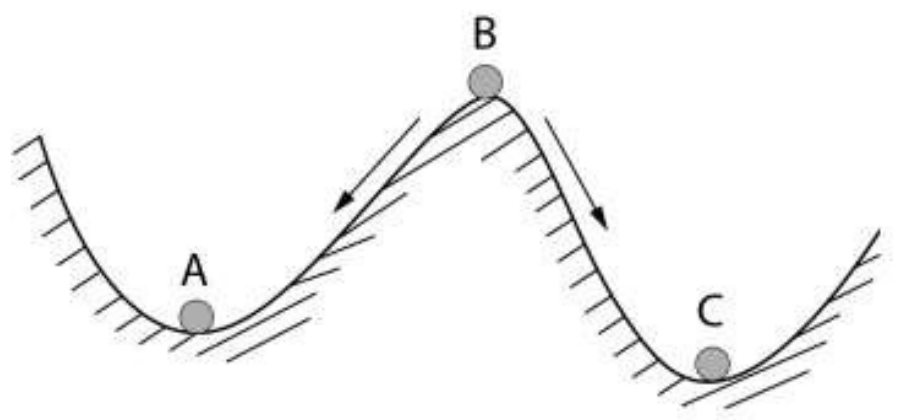

Fig. 2 "Ball-on-the-hill" anology for determining stability: Position A, C is stable, position B is unstable.

There are many kinds of bistable mechanisms, the most popular BM which applied in the micromechanisms, is presented in Fig. 3a. The BM constructed by four beam and a shuttle mass in the center. One side of the beams fixed to the anchor, another side is link to the shuttle mass. The shuttle mass move follow the y axis. Fig. 3a also illustrates the shuttle mass stay in the first equilibrium position, when the external force $\mathrm{F}$ applied to the shuttle mass, it moves to the second equilibrium position, is shown in Fig. $3 b$. 

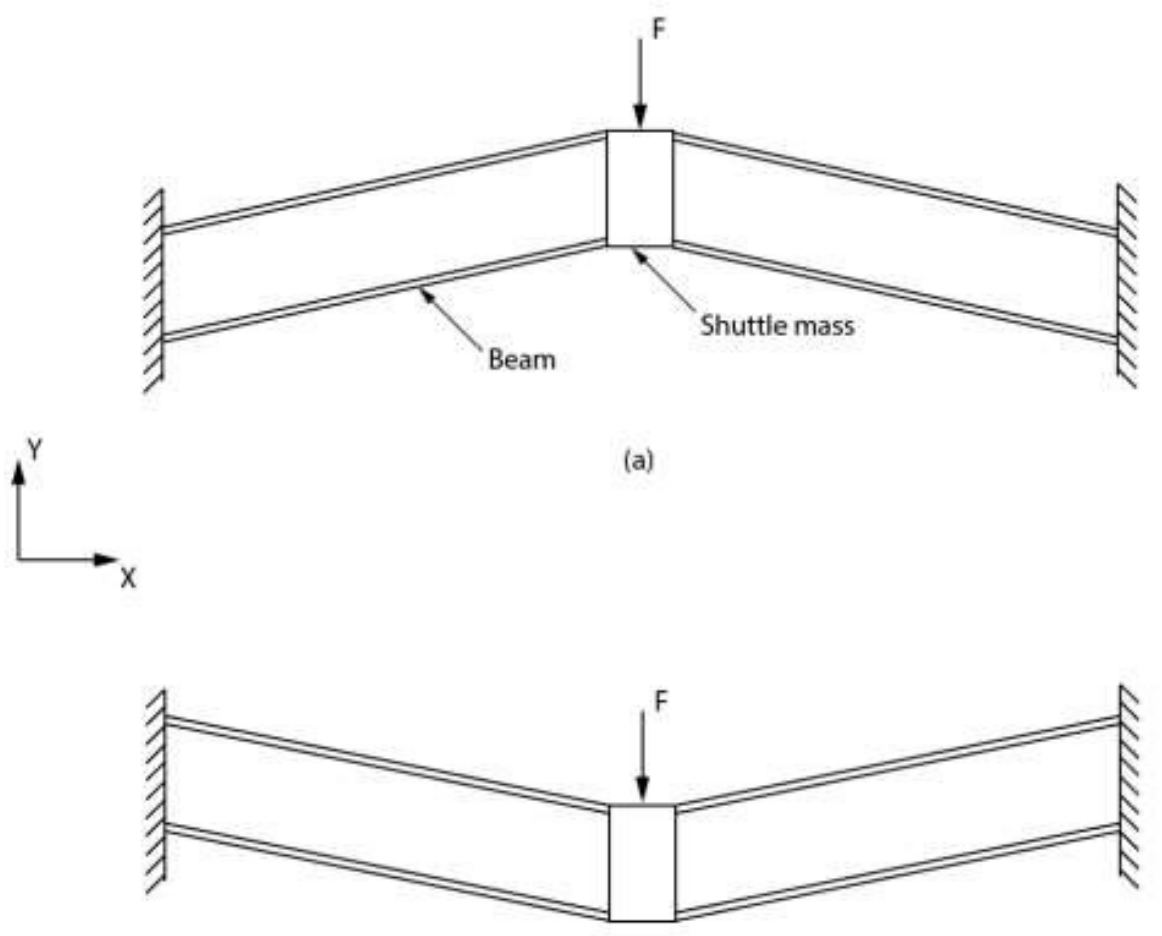

(b)

Fig 3. Operation of bistable mechanism.

A typical f-d curve of a CBM is shown in Fig. 4. At the beginning, the shuttle mass rests at its first stable equilibrium position $\mathrm{A}$. When the shuttle mass in moved quasistatically in the + direction, the sum of the reaction force at the fixed ends increases initially, attains its maximum value Fmax, then decreases and the shuttle mass reaches its unstable equilibrium position $P$. As the shuttle mass is moved further in the + direction, the reaction force turns negative, attains its minimum value Fmin, then increases and the shuttle mass reaches its second stable equilibrium position $\mathrm{C}$. While the CBM is at the unstable equilibrium position $\mathrm{B}$, a light perturbation to the $\mathrm{CBM}$ could drive the shuttle mass into the stable equilibrium positions $\mathrm{A}$ or $\mathrm{C}$. In the displacement controlled mode of motion, the positive and negative reaction forces mean that the shuttle mass is pushed and pulled in the forward motion of the mechanism, respectively. In the load controlled mode of motion, the load is increased quasistaticaly in the forward motion. When the position $\mathrm{D}$ is reached, the mechanism will snap-through toward its second equilibrium position with no appreciable change in the load. When the shuttle is moved backward, the mechanism follows the $\mathrm{f}$-d curve reversely in the displacement controlled mode of motion. 


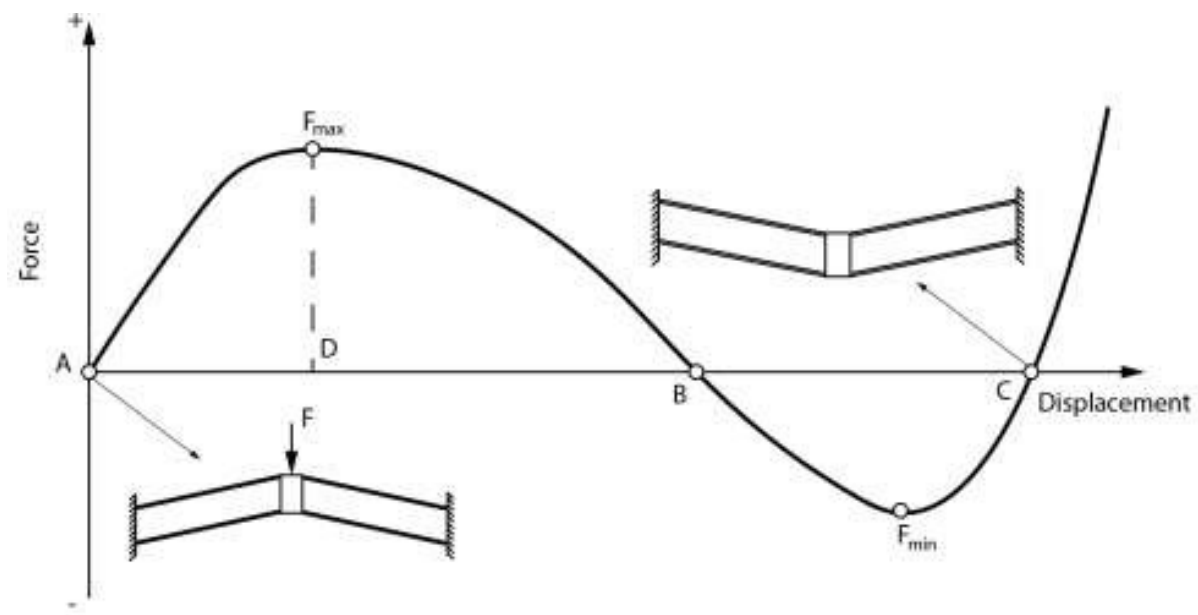

Fig 4. A typical F-d curve of bistable

\section{DESIGN AND SIMULATION}

Fig. 5 shows the typical Bézier curve with 4 control points. The cubic Bézier is specified by four control points, $\mathrm{B}_{1}, \mathrm{~B}_{2}, \mathrm{~B}_{3}$ and $\mathrm{B}_{4}$, as shown in Fig. 5(b). The parametric cubic Bézier curve is given by [11]

$$
P(t)=\left[\begin{array}{llll}
(1-t)^{3} & 3 t(1-t)^{2} & 3 t^{2}(1-t) & t^{3}
\end{array}\right]\left[\begin{array}{l}
P_{B_{1}} \\
P_{B_{2}} \\
P_{B_{3}} \\
P_{B_{4}}
\end{array}\right]
$$

where $t$ is the parameter, and $P_{B_{i}}$ is the position vector of the point $\mathrm{B}_{\mathrm{i}}$.

Fig. 6(a) is a schematic of a Bézier curved BM. Its shuttle mass is supported by four Bézier curved beams. A Cartesian coordinate system is also shown in the figure. Due to symmetry, only a half model of the mechanism is considered as show in Fig. 6(b). Dimensions of the BM and coordinates of the control points of the Bézier curve are indicated in Fig. 6(b). The thickness of the device is $20 \mu \mathrm{m}$. The anchored edges of the BM are fixed and the symmetric plane is modeled by a roller boundary condition.

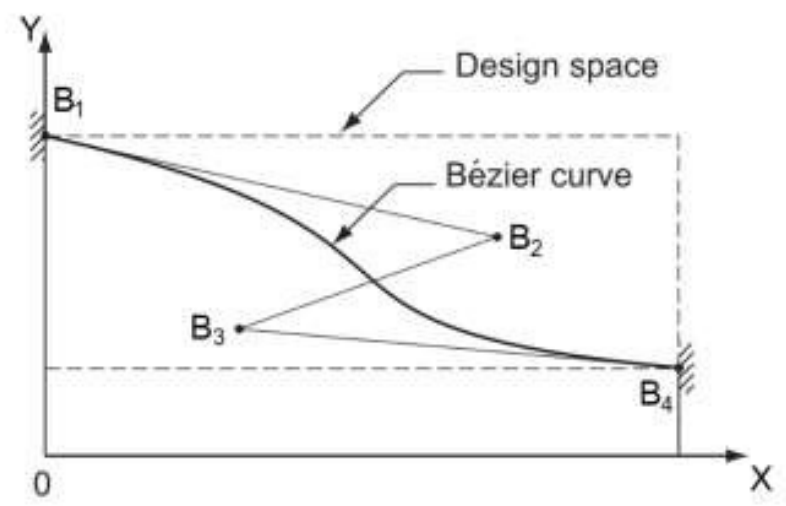

Fig. 5. A schematic of cubic Bézier with 4 control points 


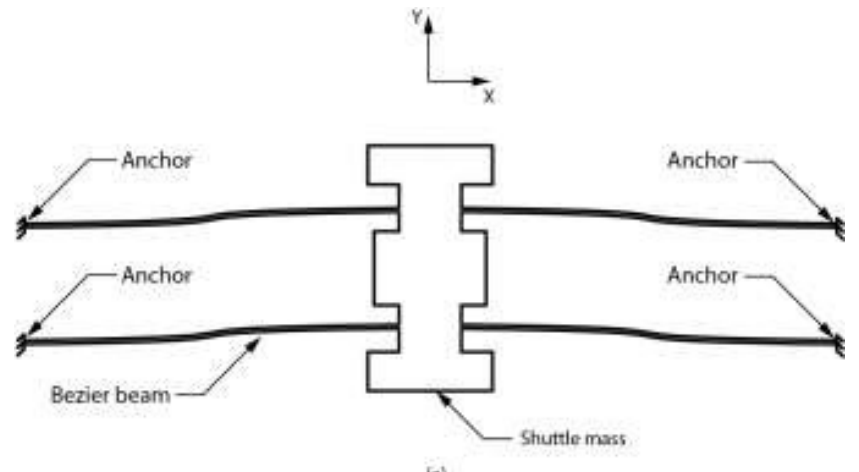

(a)

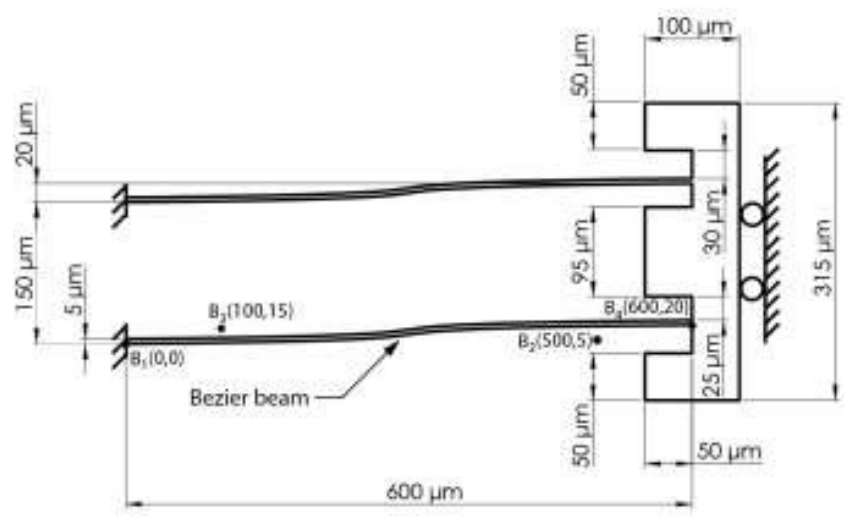

(b)

Fig. 6. (a) A schematic of the BM. (b) Dimensions of a half model.

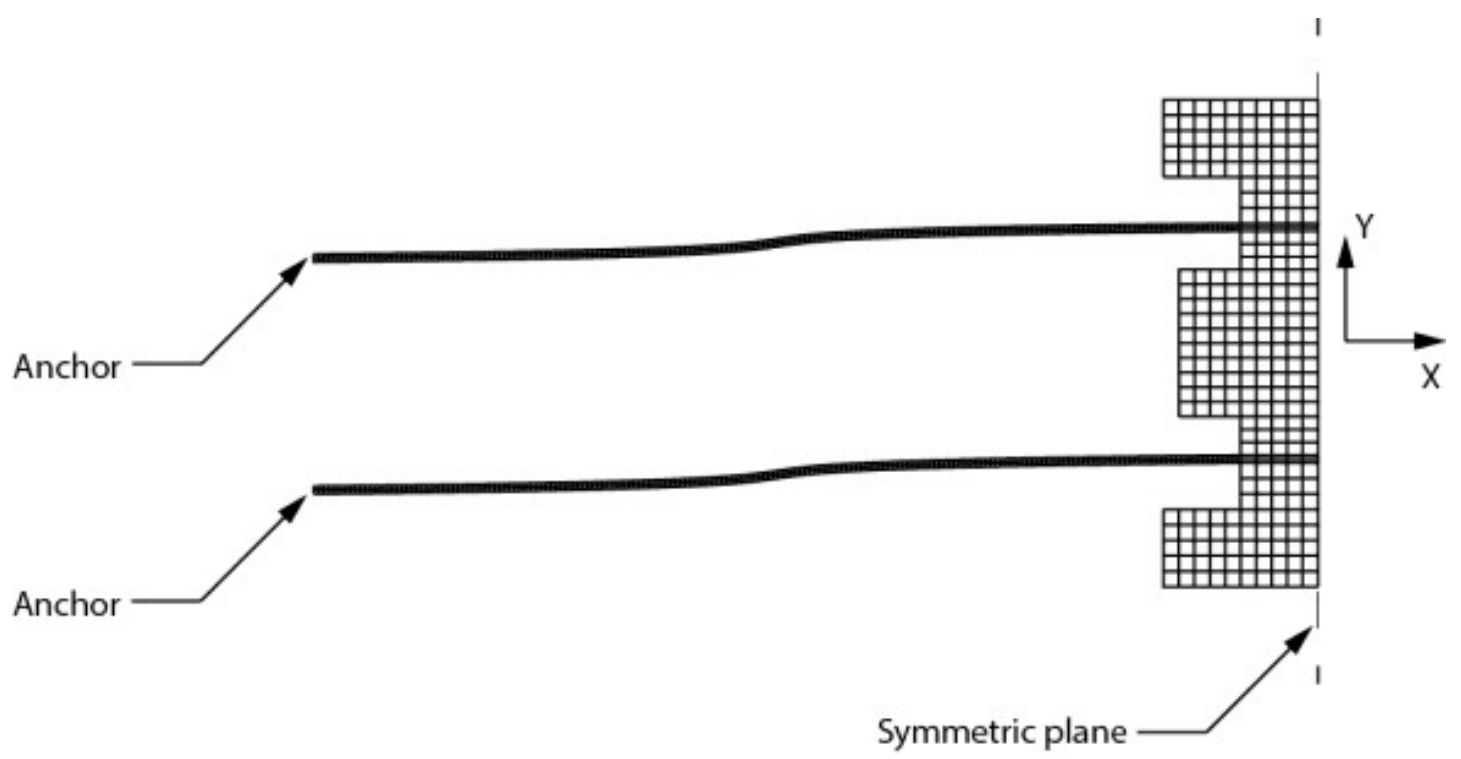

Fig. 7. A mesh of the half model. 
Finite element analyses are employed to obtain the f-d curve of the BM. A displacement of the shuttle mass in the $-\mathrm{y}$ direction is applied. The reaction force in the y direction at the fixed ends can be taken as the force applied to the BM. The $\mathrm{x}$-direction displacement of the nodes at the symmetric plane is constrained to represent the symmetry condition due to the mechanism geometry and the loading conditions. For the linear elastic and isotropic model, the Young's modulus is taken as $130 \mathrm{Gpa}$ and Poisson's ratio is 0.28 for typical silicon materials. Fig. 7 shows a mesh for the half model. The finite element model has 10804 -node elements.

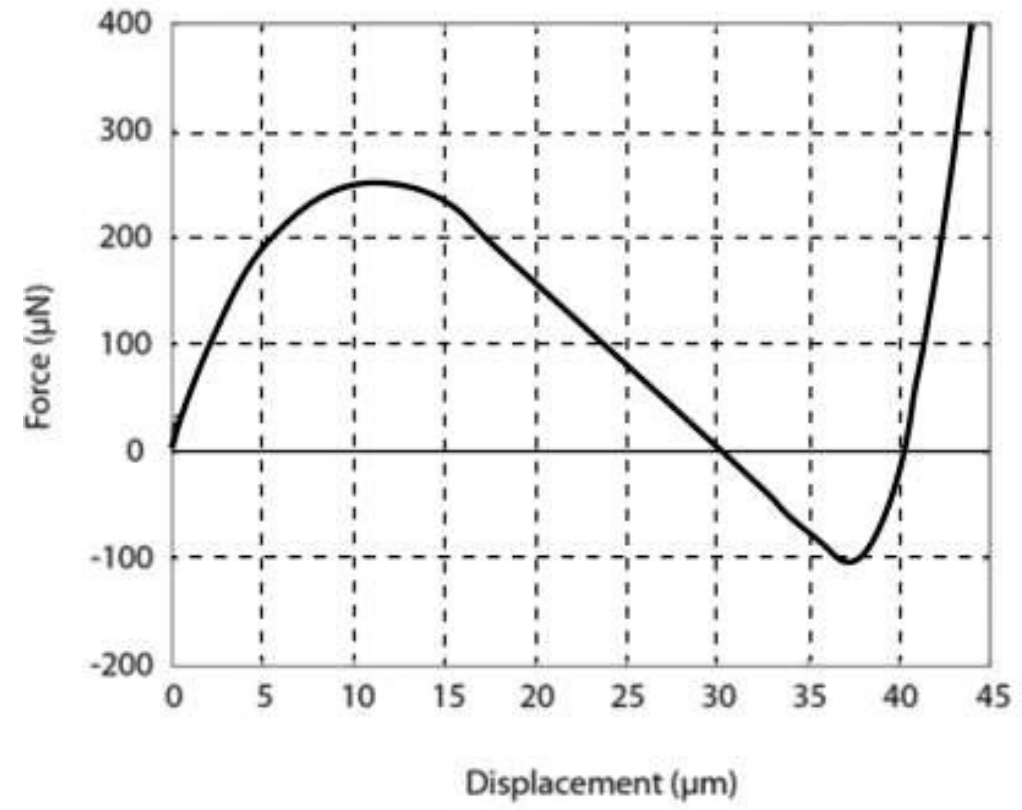

Fig. 8. F-d curve based on the finite element analysis.

A f-d curve based on the finite element analyses are shown in Fig. 8. When the displacement of the shuttle mass increases from 0 (the first stable equilibrium position), the force increases initially, reaches its maximum value at $253 \mu \mathrm{N}$, then decreases to 0 , where is an unstable equilibrium position at $30 \mu \mathrm{m}$. When the displacement continues increasing, the force decreases, attains its minimum value at $-112 \mu \mathrm{N}$, then increases again and reaches 0 , the second stable equilibrium position at $41 \mu \mathrm{m}$. The results validate the Bézier curve for design of beam profile of BMs.

\section{COMPARISION}

The f-d curve of the Bézier BM is compared with those of the cosine curved and slanted straight beam BMs, where the beams occupy the same area, $600 \mu \mathrm{m} \times 20 \mu \mathrm{m}$. The thickness and width of the beams are $20 \mu \mathrm{m}$ and $5 \mu \mathrm{m}$, respectively. The profiles of the three types of beams are shown in Fig. 9(a).The cosine curve follows the equation (2). The four control points, $\mathrm{B}_{1}, \mathrm{~B}_{2}, \mathrm{~B}_{3}$ and $\mathrm{B}_{4}$, of the Bézier beam are also indicated in the figure. The Young's modulus and Poisson's ratio of the BMs are $130 \mathrm{GPa}$ and 0.28 , respectively.

$$
y=\frac{H}{2}\left(1-\cos \left(\frac{\pi x}{L}\right)\right)
$$

Fig. 9(b) shows the f-d curves of three BMs. Table 1 gives the result of the comparision. The Bézier $\mathrm{BM}$ with the selected coordinates of the control points has the lowest switching force among the three BMs. The straight curve give the smallest distance when the BM move from the first equilibrium position to second equilibrium position and the cosine draw the biggest force in this investigation. The switching force of the Bézier BM can be adjusted by selection of the control points of the Bézier curved beam. The proposed Bézier BM provides more freedom in design of BMs. 
Table 1: Force and displacement of straight curve, cosin curve and Bézier curve.

\begin{tabular}{|c|c|c|c|}
\hline & Maximum Force $(\mu \mathrm{N})$ & $\begin{array}{c}\text { Minimum force } \\
(\mu \mathrm{N})\end{array}$ & $\begin{array}{c}\text { Second equilibrium } \\
\text { position }(\mu \mathrm{m})\end{array}$ \\
\hline Straight curve & 267 & -56 & 29 \\
\hline Cosin curve & 321 & -136 & 38 \\
\hline Bézier curve & 253 & -112 & 41 \\
\hline
\end{tabular}

\section{CONCLUSION}

A new design of BM based on Bézier curved beams is investigated. Compared to conventional BMs based on cosine curved beams and straight slanted beams, the proposed BM has high flexibility in design for BMs. Given the device area and thickness constraints, the Bézier BM has various force outputs by moving the control points of the Bézier curved beam in the design space. Based on this method, many mechanism with bistability could be designed with the same space, help save the areas of the mechanisms. Especially, in the MEMS application, with the limitation space in design, the flexible mechanism is easier to design the gripper, energy harvester device, etc. Futhermore, the Bézier curve with many control points should be observed to increase the flexibility of the mechansim. It provides more parameters so that the control is easier.

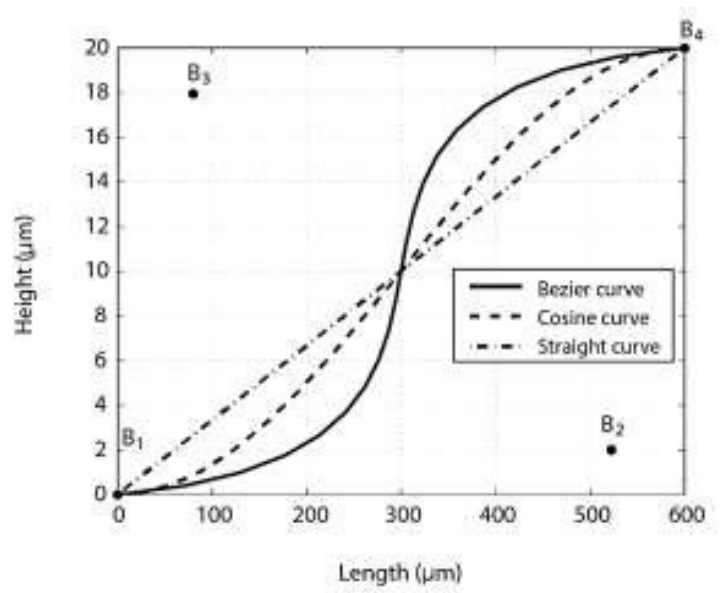

(a)

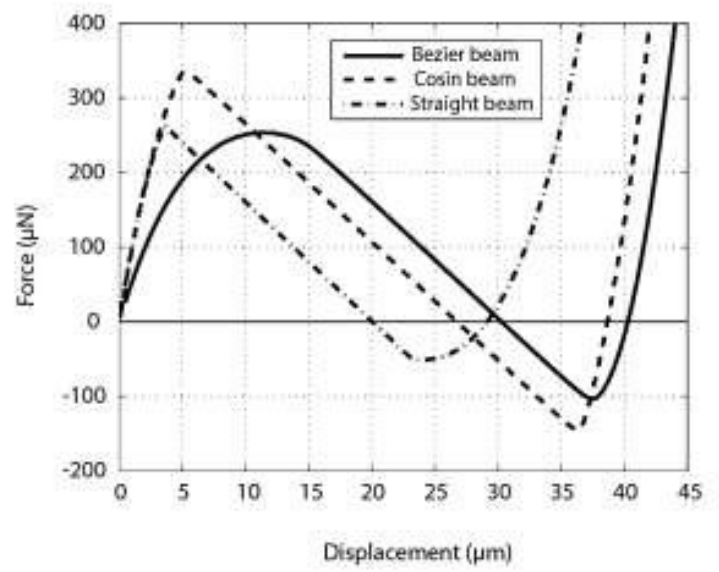

(b)

Fig. 9. (a) Profiles of and (b) f-d curves of various Bézier beams 


\section{REFERENCES}

[1] J. Qiu, J. H. Lang, and A. H. Slocum, "A curved-beam bistable mechanism", Journal of Microelectromechanical Systems, vol. 13, no. 2, pp. 137-146, 2004.

[2] C. C. Wu, M. J. Lin, R. Chen, "The derivation of a bistable criterion for double V-beam mechanisms", Journal of Micromechanics and Microengineering, vol. 23, 115005, 2013.

[3] N.D.K. Tran and D.A. Wang, Design of a crab-like bistable mechanism for nearly equal switching forces in forward and backward directions, Mechanism and Machine Theory, vol. 115, pp. 114-129, 2017.

[4] Q.D. Truong, N.D.K. Tran and D.A. Wang, "Design and characterization of a mouse trap based on a bistable mechanism”, Sensors and Actuators A: Physical, vol. 267, pp. 360-375, 2017.

[5] H.T. Pham and D.A. Wang, A constant force bistable mechanism for force regulation and overload protection, Mechanism and Machine Theory, vol. 46, pp. 899-809, 2011

[6] M. R. Brake, M. S. Baker, N. W. Moore, D. A. Crowson, J. A. Mitchell, and Jack E. Houston, "Modeling and Measurement of a bistable Beam in a Microelectromechanical System", Journal of Microelectromechanical Systems, vol. 19, no. 6, pp. 1503-1514, 2010.

[7] I. H. Hwang, Y. S. Shim and J. H. Lee, "Modeling and experimental characterization of the chevron-type bi-stable microactuator”, Journal of Micromechanics and Microengineering, vol. 13, pp. 948-954, 2003.

[8] D. L. Wilcox and L. L. Howell, "Fully Compliant Tensural Bistable Micromechanisms (FTBM)", Journal of Microelectromechanical Systems, vol. 14, no. 6, pp. 1223-1235, 2005.

[9] D.A. Wang and H.D. Nguyen, “A planar Bézier profiled horn for reducing penetration force in ultrasonic cutting”, Ultrasonic, vol. 54, pp. 375-384, 2014.

[10] L. L. Howell, “Compliant mechanism”, John Wiley \& Sons, 2001

[11] D. F. Rogers and J. A. Adams, "Mathematical elements for computer graphics", 2nd edition, McGRAWHill, New York, 1990.

\section{NGHIÊN CỨU THIẾT KẾ CƠ CẤU HAI VI TRÍ ỔN ĐỊNH CÓ LỰC NGÕ RA VỚI TÍNH LINH HOẠT CAO TRONG KHÔNG GIAN GIỚI HẠN}

Tóm tắt. Cơ cấu hai vị trí ổn định (Bistable mechanism) được sử dụng nhiều trong các chi tiết vi kết cấu, đặc biệt trong các hệ thống kẹp trong các dụng cụ y tế, sinh học. Mục tiệu của ngành chế tạo vi kết cấu đó là các cơ cấu càng nhỏ càng tốt nhưng vẫn đảm bảo tính năng hoạt động của chúng. Do đó, việc nghiên cứu, thiết kế ra các cơ cấu làm việc trong các không gian giới hạn là một trong những mục tiêu chính yếu. Dựa trên ý tưởng đó, bài báo này trình bày một cơ cấu hai vị trí ổn định mới có tính linh hoạt cao trong không gian thiết kế giới hạn bằng cách kết hợp đường cong Bezier. Đường cong Bezier với 4 điểm điều chỉnh được áp dụng để thiết kế cơ cấu này. Trong đó điểm đầu và điểm cuối của đường cong được cố định và hai điểm còn lại được thay đổi để tạo ra các biên dạng đường cong khác nhau nhưng vẫn trong không gian thiết kế có giới hạn. Đồng thời thay đổi hai điểm này cho phép tạo ra các đặc tính phi tuyến khác nhau trong cơ cấu hai vị trí ổn định. Phần mềm mô phỏng được sử dụng để phân tích đặc trưng phi tuyến trong hoạt động của cơ cấu. Bài báo cũng so sánh các cơ cấu hai vị trí ổn định gồm cơ cấu được cấu tạo bởi các đoạn thẳng, đường cosin và đường Bezier để so sánh tính linh hoạt của cơ cấu Bezier.

Từ khóa. Đường cong Bezier, cơ cấu hai vị trí ổn định, vi kết cấu.

Ngày nhận bài: 17/06/2019

Ngày chẩp nhận đăng: 18/10/2019 
Tạp chi Khoa học và Công nghệ, Số 40, 2019

\title{
DISTRIBUTED FORMATION CONTROL AND OBSTACLE AVOIDANCE OF MULTI-ROBOT SYSTEM
}

\author{
HÀ TRỌNG NGHĨA, TRẦ THANH KÊT, NGUYỄN TẤN LUỸ \\ Faculty of Electronics Technology, Industrial University of Ho Chi Minh City \\ nguyentanluy@iuh.edu.vn
}

\begin{abstract}
This paper proposes a distributed control method for multi-mobile robots to avoid obstacles. Firstly, the Limit Cycle (LC) method is exploited to set the reference trajectory for robots to avoid obstacles. Secondly, the control rule that control a leading robot following the reference path is introduced. Thirdly, the algorithm that controls robots moving in a formation and avoiding obstacles based on the combination of the LC method and the reference trajectory tracking algorithm. Different from the distributed control algorithm in related documents, the algorithm in this paper ensures that the robot formation is not only maintained but also avoids obstacles when moving to the target. Finally, simulation and experimental results are conducted to verify the effectiveness of the proposed method.
\end{abstract}

Keywords: Obstacle Avoidance, Formation Control, Nonholonomic Mobile Robots, Control Architectures, Tracking Control.

\section{INTRODUCTION}

Robots are increasingly used in life to meet practical needs such as cargo robots, search and rescue robots, adventurous robots, ... Robots can replace human to work in environments with extreme conditions, toxic to human's health ... Recently, research is focused on the study of robot control according to swarm behavior of wild animals. The research directions are only control a single robot attached to the reference angle [3] [4], but these above studies ignore the reference position. There are also many research projects study on controlling a robot attached to the position, reference angle [1] [5]. Therefore, we can combine these algorithms above to create a more complete algorithm to control the robot smoothly.

In many practical applications, when operating a moving robot formation that encounters obstacles, we need a flexible algorithm that can find the trajectory of avoiding the obstacle in the most efficient way. As robots move in warehouses, when encountering obstacles on the road or another robot is on the way, the control algorithm must be flexible to find the path while being safe and most effective. Recently, although there have been many obstacle avoidance algorithms, such as using potential field methods [9], avoiding obstacle with ultrasonic sensor [10], using LC method to find out reference trajectory [3]. The LC method is best suited to the requirements of this paper and has the most flexible problem-solving capabilities. Some studies use the LC method to find out the reference trajectory then applying the backstepping kinematics to control the robot moving to the target [4] [5]. However, they are still not applied to a formation of many robots.

Compared to the existing literature, the new contributions of this paper are listed as follows: 1) exploiting a method to avoid obstacles for single robots to solve the problem of distributed formation control and obstacles avoidance of multi-robot system. 2) designing feedback control law to ensure that when robots avoid obstacles, the stable formation is remained.

The rest of this paper is organized as follows: Section 2 introduces the theoretical basis of limit cycle and reference trajectory tracking, proposed an algorithm to control the distributed formation and obstacles avoidance of multi-mobile robot system. Sections 3 and 4 are simulation and experimental results. Section 5 is the conclusion of the paper. 